\title{
Caesarean section and left femur fracture in breech presentation in a primipara
}

Pranav Kumar Dave, P Chouhan, V Gupta, R Mishra, M Jain, M Bapat, M Tilgam, A Patidar, P Patil, C Dave, SA Faruqui

Corresponding author: Dr Pranav Kumar Dave, Asso. Prof. Deptt. of Radiology, E-7/540, MIG Senior, Arera Colony, Bhopal- 462016, MP, India; Email - pranavkdave@rediffmail.com

Distributed under Attribution-Non Commercial - Share Alike 4.0 International (CC BY-NC-SA 4.0)

\begin{abstract}
Fracture of femur of new born is rare during normal delivery or caesarean section. It may occur in difficult delivery in new born or after caesarean section due to unnoticed trauma at the time of extraction of baby. Usually noticed immediately after birth as swelling of thigh. We report the case of a female new born caesarean section delivered with fracture of left femur in primipara with breech presentation.
\end{abstract}

Caesarean section (CS) is a common indication in cases of breech presentation to prevent trauma ${ }^{1}$. Femur fracture in $\mathrm{CS}$ is rare ${ }^{2}$. The incidence of fracture of femur was reported 0.077 to 0.13 per 1000 deliveries ${ }^{3,4}$. Reported incidence of birth injuries is about $2 \%$ and $1.1 \%$ in singleton vaginal deliveries of fetuses in cephalic position and caesarean deliveries respectively ${ }^{5,6}$. Clavicle, humerus and femur fractures are the most common fractures during normal vaginal delivery. The incidence of birth associated injuries or fracture has reduced with caesarean section delivery ${ }^{7}$. Mostly fracture femur is diagnosed on the day of birth or following day ${ }^{3,5,6}$. Birth related fracture of femur is diagnosed immediately after birth in cases of difficult extraction most of the time. Abnormal cracking sounds are heard at time of birth.

Case

A 23 years old primigravida was planned for LSCS under spinal anesthesia for breech presentation at 38 weeks of pregnancy. A female newborn weighing $2.6 \mathrm{~kg}$ body weight
Keywords: Caesarean section, fracture, femur, breech.

was delivered after CS. Antenatal sonography was unremarkable except suggestive of breech presentation. There was cry of baby at the time of birth without any resuscitation support. A swelling of left thigh region was

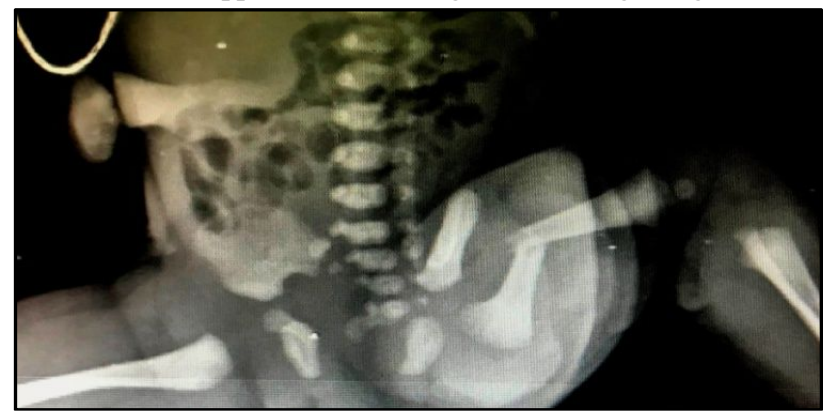

Figure 1: Radiograph of left femur after birth - fracture shaft of femur.

noticed immediately after birth. No other abnormality was seen in new born. There was no wound, muscular hypotonia, hearing impairment or blue sclera in new born. Skiagram revealed fracture of mid shaft of left femur (Figure 1). The

Received: $29^{\text {th }}$ November 2019. Accepted: $27^{\text {th }}$ January 2020 .

Dave PK, Chouhan P, Gupta V, Mishra R, Jain M, Bapat M, et al. Caesarean section and left femur fracture in breech presentation in a primipara. The New Indian Journal of OBGYN. 2020; 7(1): 102-4. 
possibility of abuse or an underlying disease as congenital

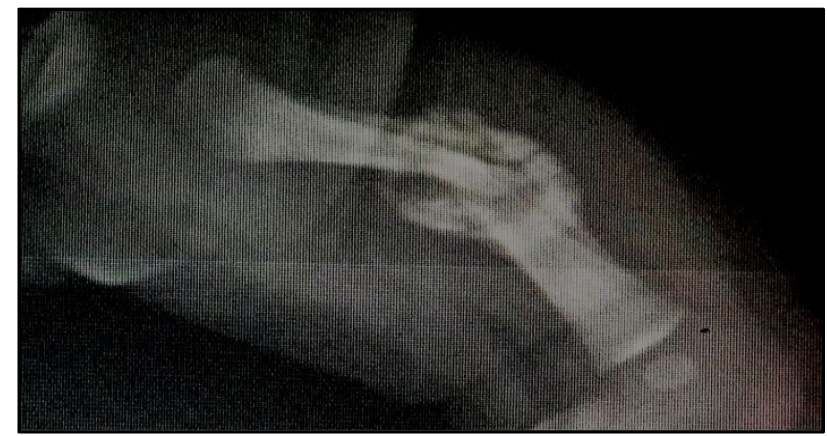

Figure 2: Radiograph of left femur - fracture shaft with callus formation

osteoplasia was ruled out. Left limb was immobilized with support. Baby responded well and a follow up skiagram revealed good callus formation and remolding of bone (Figure 2). Fracture was completely united in 3 months duration (Figure 3). After 7 months there was no evidence of

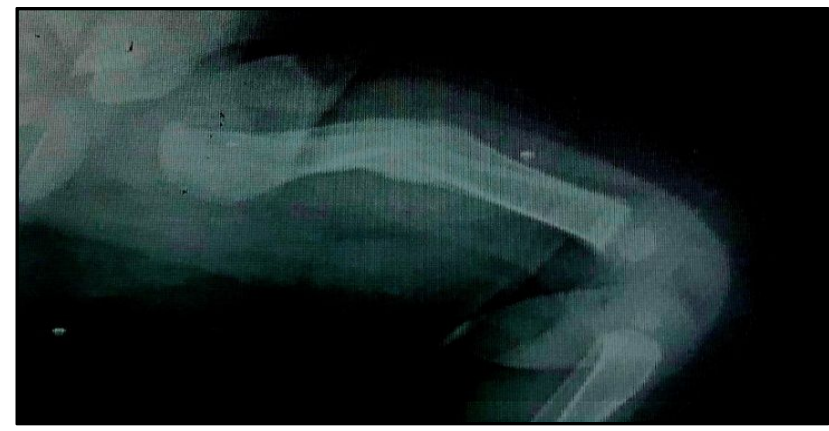

Figure 3: Radiograph of left femur - callus formation after 3 months

transformation and any difference in length of both femur (Figure 4). Child had normal movement of left lower limb during crawling.

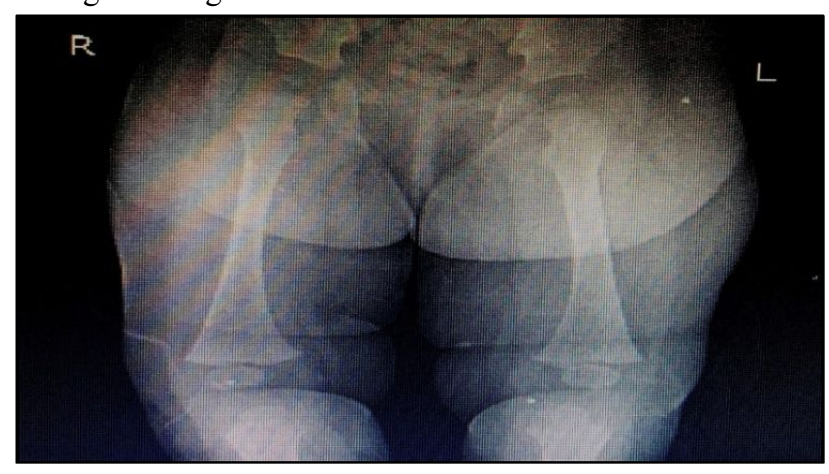

Figure 4: United fracture with remoulding left femur.

\section{Discussion}

There are very few reports of bone fracture in $\mathrm{LSCS}^{7}$. Fracture of femur, depressed fracture of skull, fracture of tibia, radius and rarely of humerus in difficult breech extraction are reported in literature ${ }^{8-14}$. Fractures may occur following difficult deliveries where considerable traction was needed. Maneuvers used during CS, inadequate uterine incision and relaxation may cause these fractures or in a situation where the breech is well engaged in pelvis or when a footling has descended into vagina. Large fetuses, breech presentation difficult delivery, inadequate uterine relaxation, small incision, twin pregnancies, osteogenesis imperfecta, prematurity and osteoporosis are the risk factors speculated to be associated with fracture of femur during $\mathrm{CS}^{3}$.

Fracture of femur during CS at birth is diagnosed early because of difficult extraction and or with abnormal cracking sound noted at birth. But some time lack of symptoms delay the diagnosis of some birth related femur fractures ${ }^{1}$. Therefore these can be classified according to the day of diagnosis, those diagnosed on the day of birth and those diagnosed after postpartum day ${ }^{3}$. Usual presentation is as soft tissue swelling, joint stiffness, focal tenderness and some irritability are late findings and may explain the delayed diagnosis .Very rarely there may be bilateral femur fracture ${ }^{15-16}$. -The exact technique of maneuvering new born during CS and to avoid this complication of fracture of femur during CS is not precisely mentioned in the literature. However with an adequate analgesia, smooth proper relaxation, sufficiently wide incision and caution during extraction of new born could avoid this rare complication during CS. It is recommended to extend the uterine incision rather than continue to exert traction which becomes difficult and dangerous. The cracking sound is an important sign of breaking the femur of the new born during extraction ${ }^{17}$. Radiograph of the lower limb of new born confirms the diagnosis. Rajesh Rai et $\mathrm{al}^{18}$ reported the common fractures in complicated deliveries as clavicle $(45.7 \%)$, humerus (20\%), femur (14.3\%) and depressed skull fracture (11.4\%). Various treatment modalities are described for fracture of femur as immobilization, gallows traction, spica cast and Pavlik harness $^{19}$. In our case immobilization was applied for 6 weeks duration.

\section{Conclusion}

There are chances of less injury to the new born in CS as compared to vaginal delivery. Fracture of femur during caesarean section for breech presentation is not common. 
Therefore newborn who are delivered using CS, particularly in breech presentation should be carefully evaluated by the attending pediatrician / neonatologist. With immobilization there is good healing of fracture. However proper counseling of mother is very important to continue breast feeding, which plays an important role for newborn and mother to cope up with such an event.

\section{Conflict of interest: None. Disclaimer: Nil.}

\section{References}

1. Kanai Y, Honda Y, Honda T, Sanpei M. Delayed BirthRelated Femur Fracture after Cesarean Section: A Case Report. American Journal of Reintology Reports. 2018; 8(3): e158-e160.

2. Kancherla R, Sankineani SR, Naranje S, Rijal L, Kumar $\mathrm{R}$, Ansari $\mathrm{T}$, et al. Birth- related femoral fracture in newborns: risk factors and management. J Child Orthop. 2012; 6(3):177-80

3. Morris S, Cassidy N, Stephens M, McCormark D, McManus F. Birth associated femoral fracture: incidence and outcome. J Pediatr Orthop. 2002; 22(1): 27-30

4. Toker A, Perry ZH, Cohen E, Krymko H. Cesarean section and the risk of fractured femur. Isr Med Assoc J. 2009;11(7): 416-8

5. Alexander JM, Leveno KJ, Hauth J, Landon MB, Thom E, Spong CY, et al. Fetal injury associated with caesarean delivery. Obstetrics \& Gynecology. 2006; 108(4): 885-90

6. Demissie K, Rhoads CG, Smulian JC, Balasubramanian BA, Gandhi K, Joseph KS, et al. Operative vaginal delivery and neonatal and infants adverse outcomes: population based retrospective analysis. British Medical Journal. 2004; 329(7456): 24-9.

7. Thakkar UG, Mishra VV, Vanikar AV, Agrawal RS, Kadam PG. Fracture of shaft of left femur in a newborn delivered by caesarean section. Sri Lanka Journal of Child Health. 2015; 44 (1): 53-5.

8. John BM, Roy S, Gupta G, Wilson CG. A case of fracture in a newborn delivered by caesarean section, Medical Journal Armed Forces India. 2004; 60: 194-5.

9. Rija L, Ansari T, Trikha V and Yadhav CS. Birth injuries in caesarean sections: cases of fracture femur and humerus following caesarean section. Nepal Medical College Journal. 2009; 11 (3): 207-8.
10. Kellner KR. Neonatal fracture and cesarean section. American Journal of Children. 1982; 136(9): 865.

11. Barnes AD, Van Geem TA. Fracture femur of the newborn at cesarean section - A case report. Journal of Gynecologist. 1985; 30(3): 203-5.

12. Vasa R, Kim MR. Fracture of the femur at cesarean section: case report and review of literature. American Journal of Perinatology. 1990; 7(1): 46-8.

13. Awwad JT, Nahhas DE, Karam KS. Femur fracture during cesarean breech delivery. International Journal of Gynecology and Obstetrics. 1993; 43(3): 324-6.

14. Capobianco G, Virdis G, Lisai P, Cherchi C, Biasetti O, Dessole F, et al. Cesarean section and right femur fracture: a rare but possible complication for breech presentation. Case reports in obstetrics and gynecology. 2013 Mar 6; 2013: 613709

15. Cebesoy FB, Cebesoy O, Incebiyik A. Bilateral femur fracture in a newborn: an extreme complication of cesarean delivery. Arch Gynecol Obtet. 2009; 279(1): $73-4$

16. Campolat FE, Kose A, Yurdakok M. Bilateral femur fracture in a neonate after cesarean delivery. Archives of Gynecology and Obstetrics. 2010; 281: 967-9.

17. Matsubara S, Izumi A, Nagai T, Kikkawa I, Suzuki M. Femur fracture during abdominal breech delivery. Arch Gynecol Obstet. 2008; 278(2): 197-7.

18. Rai R, Kolhe S, Shukla K. Right Femur Fracture during Caesarean Delivery. Journal of Neonatology. 2017; 31: 44-7.

19. Hannah ME, Hannah WJ, Hewson SA, Hodnett ED, Saigal S, Willan AR. Planned caesarean section versus planned vaginal birth for breech presentation at term: a randomized multicenter trial. 2000; Lancet: 356(9239): $1375-83$

\footnotetext{
Pranav Kumar Dave ${ }^{1}$, P Chouhan ${ }^{2}$, V Gupta ${ }^{3}$, R Mishra ${ }^{4}$, M Jain ${ }^{5}$, M Bapat ${ }^{6}$, M Tilgam ${ }^{7}$, A Patidar ${ }^{8}$, P Patil $^{9}$, C Dave ${ }^{10}$, SA Faruqui ${ }^{11}$

${ }^{1}$ Associate Professor, ${ }^{2}$ Resident; ${ }^{3}$ Professor, ${ }^{4}$ Professor, ${ }^{5}$ Professor and HOD, ${ }^{6}$ Assistant Professor,

${ }^{7}$ Resident, ${ }^{8}$ Resident, Department of Radiodiagnosis;

${ }^{9}$ Professor, Department of Obstetrics and Gynaecology; ${ }^{10}$ Ex. Assistant Professor, Department of Paediatrics; ${ }^{11}$ Ex Professor, Department of Orthopaedics .
} 